\title{
Aproveitamento do lodo gerado em sistema de decantação para o traço de concreto não estrutural
}

\author{
Mateus Viana Azevedo', Leonardo Filippi Vicenzi', Fernando Ernesto Ucker', \\ Anna Paula Ferreira Batista Goldfeld Ucker', Marcelo Tsuyoshi Haraguchi', \\ Felipe Corrêa Veloso dos Santos', Pedro Daniel da Cunha Kemerich ${ }^{2}$, Willian Fernando Borba ${ }^{3}$

\footnotetext{
' Laboratório de Planejamento e Monitoramento Ambiental - LPMA/UFSM, Curso de Engenharia Ambiental da Universidade Federal de Santa Maria/CESNORS, Frederico Westphalen, Brasil.

${ }^{2}$ Coordenador do Curso de Engenharia Ambiental da Universidade Federal de Santa Maria/CESNORS, Frederico Westphalen, Brasil.

3 Técnico em Agropecuária, Aluno de Graduação do Curso de Engenharia Ambiental, Universidade Federal de Santa Maria, Santa Maria, Brasil.
}

\section{Resumo}

A fim de dar destinação para o lodo gerado da lavagem de caminhões betoneiras em concreteiras, avaliou-se sua utilização em substituição de parte da areia fina e grossa no traço de concretos convencionais. Para isto, foram utilizados dois tipos de lodos, o tipo 01 , com experimentos de 5 e $10 \%$ de substituição da areia pelo lodo, e o lodo tipo 02 , com a areia substiuida nas proporções de $5,10,25$ e $50 \%$ pelo lodo em cada traço rodado. Verificou-se, então, a resistência à compressão dos corpos de prova de cada traço. O traço testemunha obteve resistência, aos 28 dias, de 19,70 MPa. Também aos 28 dias, para o Lodo 01, as resistências foram de 17,80 MPa para 5\% e de 16,40 MPa para 10\% de substituição. Para o Lodo 02, as resistências aos 28 dias foram de 21,65 MPa para 5\%, 23,03 Mpa para 10\%, 19,23 MPa para $25 \%$ e de 18,18 MPa para $50 \%$.

Palavras-chave: construção civil, reaproveitamento, concreto

\begin{abstract}
In order to destination for the sludge generated from washing concrete mixers trucks for concrete producers, we evaluated its use in place of part of the fine and coarse sand in the trace of conventional concrete. For this, two types of sludge, type 01 experiments 5 and $10 \%$ substitution of sand by the mud were used, and the type sludge 02 substiuida with sand in proportions of $5,10,25$ and $50 \%$ by sludge rotated at each stroke. It then emerged the compressive strength of the specimens of each trait. The trace obtained witness resistance at 28 days of 19.70 $\mathrm{MPa}$. Also at 28 days to $01 \mathrm{Lodo}$, the heaters were $5 \%$ to $17.80 \mathrm{MPa}$ and $16.40 \mathrm{MPa}$ for $10 \%$ replacement. For Sludge 02 , the resistances at 28 days were $21.65 \mathrm{MPa}$ for $5 \%, 10 \%$ to $23.03 \mathrm{MPa}, 19.23 \mathrm{MPa}$ for $25 \%$ and $50 \%$ to $18.18 \mathrm{MPa}$.
\end{abstract}

Keywords: construction, recycling, concrete 


\section{INTRODUÇ̃̃o}

A região Centro-Oeste foi responsável pela produção de 1.669.502 toneladas de cimento em 2012, dos quais 1.175.953 toneladas foram utilizadas em concreteiras (SNIC, 2013). Para isto, adotando-se um consumo médio de $300 \mathrm{~kg} / \mathrm{m}^{3}$, pode-se estimar que a produção de concreto na região Centro-Oeste, em 2012, foi de aproximadamente $3.919 .843 \mathrm{~m}^{3}$.

O caminhão betoneira, utilizado para transportar o concreto, deve ser lavado, a fim de evitar a contaminação com o concreto seguinte e o encrustamento dos materiais residuais dentro do balão. Tal processo requer em torno de 500 litros de água por caminhão lavado, segundo o empresário do ramo, Rodolfo Torres, e resulta em uma água altamente básica, danosa tanto aos caminhões, pela corrosão no processo de lavagem, quanto ao meio ambiente.

As pressões dos órgãos ambientais, aliadas à possibilidade de ganhos financeiros, levaram ao aparecimento dos "bate lastros" nas concreteiras. Trata-se de uma estrutura voltada para a lavagem de caminhões betoneiras, que conta com sistema de filtragem e decantação da água utilizada, para que se possa fazer o reuso no amassamento (PETCIVIL UFJF, 2012).

À margem dos principais estudos sobre o assunto está o lodo gerado no processo de decantação durante o reaproveitamento da água. O resíduo, assim como a água, também é básico e traz sérios prejuízos à natureza quando descartado de forma incorreta. Ucker, Barroso e Lopes (2010) constataram a possibilidade e a viabilidade do uso deste lodo como agregado para o amassamento de novo concreto, trazendo o material de volta ao ciclo, em vez de realizar um descarte impróprio.

Aliada à necessidade de se produzir cada vez mais, de forma sustentável, estão as pressões para que o setor da construção civil diminua o impacto de suas ações. Dentro deste contexto, esse estudo se justifica pela necessidade de se produzir, dentro do setor da construção civil, de forma mais sustentável, poupando recursos naturais na fabricação do concreto e evitando a destinação final incorreta dos materiais gerados pelo reuso de água nas concreteiras, que comumente são despejados em mananciais ou, diretamente, no solo.

Este trabalho tem como objetivo avaliar a utilização do lodo proveniente do sistema de decantação de uma indústria de concreto, como parte dos agregados no amassamento do concreto.

\section{METODOLOGIA}

Foi realizada a revisão bibliográfica acerca dos principais temas abordados nesta pesquisa, de forma a verificar a viabilidade da utilização do lodo, em substituição da areia, no preparo de concretos. Desenvolveu-se um estudo de caso na empresa Realmix Concreto Ltda., uma concreteira com expressivo mercado no estado de Goiás, localizada na avenida W-006, em Aparecida de Goiânia, próximo a BR-153, saída para São Paulo.

A Realmix Concreto Ltda. conta com o sistema bate lastro para reaproveitamento da água utilizada na lavagem dos caminhões betoneiras. Neste sistema, toda água utilizada na lavagem dos caminhões é captada e conduzida, por um canal, até doze decantadores (Figura 1). Após a decantação do material particulado, a água é novamente utilizada no processo de amassamento de concreto.

Foram utilizados dois tipos diferentes de lodo, ambos extraídos, manualmente, por meio de pás: o lodo tipo 01, que foi extraído do fundo dos decantadores e é proveniente do tratamento da água utilizada, e o lodo tipo 02 , proveniente da piscina de lavagem, local onde é feita uma pré-lavagem, retirando-se, de forma grosseira, a maior parte do material residual dos caminhões betoneiras, antes dos caminhões serem encaminhados para a lavagem.

Após a retirada dos lodos tipo 01 e tipo 02 , estes passaram por um processo de secagem ao ar por 24 horas. Decorrido o tempo inicial e constatada a presença de umidade, os lodos foram transportados em sacos para um laboratório da Pontifícia Universidade Católica de Goiás, localizado no Setor Universitário, na área 03 de Engenharia Civil, e inseridos em estufa, onde a temperatura foi mantida em $105 \pm 5^{\circ} \mathrm{C}$, até remoção total da umidade. Sem a presença de umidade foi possível determinar suas principais características e realizar a análise granulométrica do material, passando pelas peneiras das séries normal, com malhas variando entre 0,075 e $4,80 \mathrm{~mm}$, com tampa e fundo, por meio de agitação manual, seguindo o ponderado pela Norma Mercosul, adotada pela ABNT como normal brasileira, NBR NM 248 (ABNT, 2001).

A massa mínima de material a ser peneirado, de acordo com a NBR NM 248 (ABNT, 2001), é de 300 gramas para agregados com dimensão máxima nominal menor que $4,75 \mathrm{~mm}$, como os materiais analisados. Neste trabalho foram utilizadas amostras de 500 gramas do material.

A dimensão máxima característica, que é a 


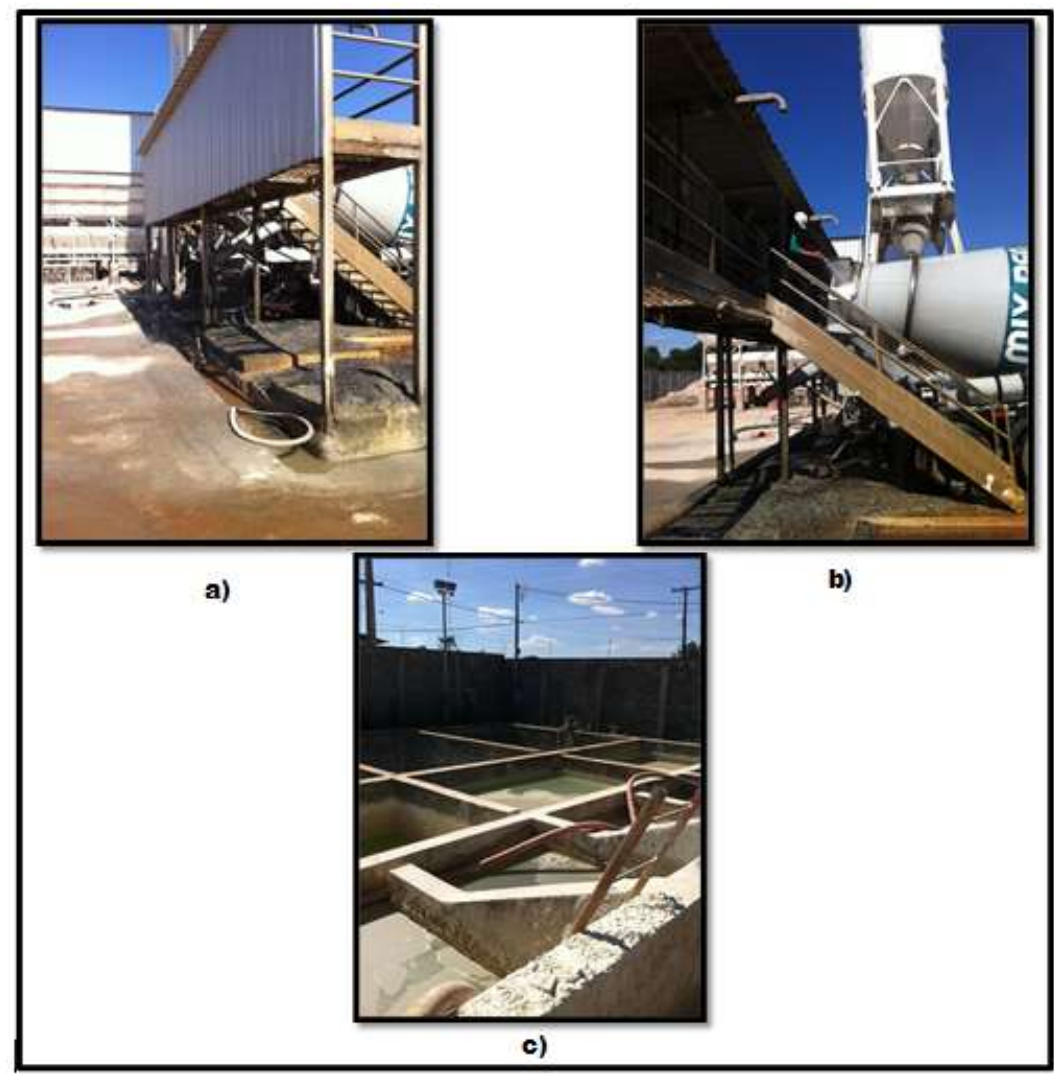

Figura 1 - a) Captação da água usada na lavagem; b) Lavagem dos caminhões; c) Decantadores instalados na empresa.

Tabela 1 - Traço Testemunha Utilizado. A/C = Relação água/cimento.

\begin{tabular}{lcccccc} 
Material & Gimento & Areia Fina & Areia Grossa & Brita 0 & Brita 1 & AfC \\
\hline Quantidade & $3 \mathrm{Kg}$ & $\mathbf{3 , 1 8 K g}$ & $4,75 \mathrm{Kg}$ & $3,3 \mathrm{Kg}$ & $4,25 \mathrm{Kg}$ & 0,7 \\
\hline
\end{tabular}

abertura, em milímetros, da malha da peneira que apresenta uma porcentagem acumulada retida de agregado igual ou inferior a $5 \%$ em massa (NBR 7211, 2009), foi encontrada após o peneiramento. Também foi calculado o módulo de finura, ou seja, a soma das massas dos lodos retidos, acumuladas em cada peneira, dividida por 100 (NBR 7211, 2009).

Para que fosse possível conhecer a resistência de concretos com a substituição de parte da areia pelos lodos, foram rodados traços com diferentes proporções de lodo como agregado miúdo, além de um traço testemunha sem substituição alguma, com a finalidade de servir como referência para os ensaios. $\mathrm{O}$ traço rodado para moldagem do corpo de prova testemunha teve a seguinte composição, expressa na Tabela 1.

Em cada traço se substituiu uma porcentagem da massa total de areia presente no traço testemunha, substituindo esta porcentagem, tanto de areia grossa como de areia fina, pelos lodos. Foram rodados seis traços com substituição da areia pelo lodo, cada traço teve substituição nas seguintes proporções, conforme o Quadro 1.

Quadro 1 - Proporção de substituição de areia por lodo em cada traço.

\begin{tabular}{|l|c|c|}
\hline TRAÇO & $\begin{array}{c}\text { \% DE AREIA } \\
\text { SUBSTITUIDA } \\
\text { POR LODO 01 }\end{array}$ & $\begin{array}{c}\text { \% DE AREIA } \\
\text { SUBSTITUIDA } \\
\text { POR LODO 02 }\end{array}$ \\
\hline TRAÇO 01 & $5 \%$ & - \\
\hline TRAÇO 02 & $10 \%$ & - \\
\hline TRAÇO 03 & - & $5 \%$ \\
\hline TRAÇO 04 & - & $10 \%$ \\
\hline TRAÇO 05 & - & $25 \%$ \\
\hline TRAÇO 06 & - & $50 \%$ \\
\hline
\end{tabular}


O abatimento do tronco de cone, determinado para confecção de sarjetas na recuperação da Avenida Paulista, em São Paulo, em 2008, pela Prefeitura de São Paulo, foi de $60 \pm 10 \mathrm{~mm}$. (PMSP-SMSP, 2008). Admitindo-se a confecção de sarjetas como bom teste para o concreto testado neste trabalho, devido a não existência de função estrutural imprescindível e por não se fazer necessário uso de armadura, adotou-se, para todos os traços, abatimento de $60 \pm 10 \mathrm{~mm}$.

Nos primeiros ensaios foram rodados concretos com o lodo 01 e o lodo 02 , com proporções de 5 e $10 \%$ da areia substituída. Os primeiros resultados sugeriram queda progressiva de resistência com a utilização do lodo 01 e o aumento com a utilização do lodo 02. Com isso, o foco do trabalho voltou-se para o lodo 02 , com a realização de novos ensaios, dessa vezl substituindo a areia do traço em 25 e $50 \%$.

Para moldagem dos corpos de prova, para realização dos ensaios de compressão, foram utilizados os seguintes materiais e equipamentos:

- Areia fina e grossa;

- Brita 0 e brita 1 ;

- Cimento Portland (CP II Z 32);

- Àgua potável;

- Balança digital Toledo, com resolução

maior que $0,01 \%$ de todas as massas medidas;

- Moldes (Corpos de prova cilíndricos com dimensões10x20 cm);

- Soquete (Haste metálica);

- Colher de pedreiro;

- Espátula;

- Régua graduada;

- Pipeta graduada para medição da quan-

tidade de água;

- Cone de abatimento;

- Misturador mecânico (Betoneira de 75 litros).

Os materiais foram pesados em balança digital aferida e colocados na betoneira, onde foram rodados até atingirem uma composição homogênea. Foi feito o ensaio de abatimento de tronco de cone e, depois de alcançados os valores de $60 \pm 10 \mathrm{~mm}$ de abatimento, medido com régua graduada, foram moldados os corpos de prova segundo a NBR 5738 de 2003/emenda 2008, Concreto - Procedimentos para moldagem e cura dos corpos-de-prova (ABNT, 2008).

Após a moldagem, os corpos de prova foram colocados em câmara úmida para cura. Passadas 24 horas, os corpos de provas foram desenformados e ficaram na câmara úmida até suas respectivas datas de rompimento, de 07 e 28 dias. Os corpos de provas foram capeados com placa neoprene e o rompimento foi feito utilizando prensa hidráulica da marca EMIC, da linha PC200, com capacidade de até 200 toneladas. Os resultados foram obtidos através do software TESC, apropriado para o modelo, EMIC, de prensa utilizado.

\section{RESULTADOS E DISCUSSÃO}

A dimensão máxima característica do lodo 01 foi de $2,40 \mathrm{~mm}$, sendo que este apresentou $10,80 \%$ de material pulverulento. $\mathrm{O}$ módulo de finura encontrado foi de 5,07. O material fino, menor que $0,15 \mathrm{~mm}$, representou $29,66 \%$ do total de material (Tabela 2).

Tabela 2 - Porcentagem de lodo 01 retido em cada peneira.

\begin{tabular}{cc}
$\begin{array}{c}\text { Peneiras } \\
\text { (mm) }\end{array}$ & $\begin{array}{c}\text { Determinação } \\
\text { \% retida }\end{array}$ \\
\hline 4,80 & 0,00 \\
2,40 & 0,00 \\
1,19 & 39,57 \\
0,59 & 16,87 \\
0,42 & 7,43 \\
0,30 & 6,47 \\
0,15 & 16,96 \\
0,075 & 1,90 \\
fundo<0,075 & 10,80 \\
\hline
\end{tabular}

O lodo 02 obteve resultados similares ao lodo 01 em seu peneiramento, também com $100 \%$ do material passante pela peneira de $2,40 \mathrm{~mm}$. Enquanto o lodo 01 teve $43,56 \%$ do material passante pela peneira 0,42 $\mathrm{mm}$, o lodo 02 teve $46,72 \%$. A dimensão máxima característica foi de $2,40 \mathrm{~mm}$ e o módulo de finura de 5,05. Apesar de resultados próximos, o lodo 02 apresentou grande diferença na quantidade de material pulverulento, $2,80 \%$ frente a $10,80 \%$ do lodo 01 . Já o material fino do lodo 02 correspondeu a $22,06 \%$ do total (Tabela 3).

A grande quantidade de material não passante pela peneira $1,19 \mathrm{~mm}$ do lodo 01 leva a uma menor compacidade, quanto maior as partículas maiores serão os vazios e menor será a compacidade. Já o lodo 02 apresentou resultado de $22,40 \%$ do material não passante pela peneira de $1,19 \mathrm{~mm}$.

O lodo 01 apresentou quantidade elevada de material não passante pela peneira de $1,19 \mathrm{~mm}, 39,57 \%$, enquanto o lodo 02 obteve $22,40 \%$.

O rompimento dos corpos de prova com lodo 
Tabela 3 - Porcentagem de lodo 02 retido em cada peneira.

\begin{tabular}{cc}
$\begin{array}{c}\text { Peneiras } \\
\text { (mm) }\end{array}$ & $\begin{array}{c}\text { Determinação } \\
\text { \% retida }\end{array}$ \\
\hline 4,80 & 0,00 \\
2,40 & 0,00 \\
1,19 & 22,40 \\
0,59 & 25,70 \\
0,42 & 16,12 \\
0,30 & 13,72 \\
0,15 & 16,88 \\
0,075 & 2,38 \\
fundo<0,075 & 2,80 \\
\hline
\end{tabular}

Quadro 2 - Resultado dos ensaios de resistência à compressão de cada traço. A/C é a relação água/cimento.

\begin{tabular}{|c|c|c|c|c|}
\hline \multirow[t]{2}{*}{ TRACO } & \multirow{2}{*}{$\frac{\text { REGCĀO }}{\text { AVC }}$} & ABATIENTO & $\begin{array}{c}\text { RESISTIENCIA } \\
7 \text { DIAS }\end{array}$ & $\begin{array}{c}\text { RESISTIENCAA } \\
\text { 2s dias }\end{array}$ \\
\hline & & ca & $\mathrm{MPa}$ & $\mathrm{NPa}$ \\
\hline TESTEMUNHA & 0,70 & 59 & 1672 & 1970 \\
\hline $5 \%$ DE LODO 01 & 0,77 & 50 & 15,34 & 17,80 \\
\hline 10\% DE LODO 01 & 0,80 & 6,5 & 14,95 & 16,40 \\
\hline $5 \%$ DE LODO 02 & 0,70 & 6,1 & 18,19 & 21,65 \\
\hline 10\% DE LCDO 02 & 0,69 & 5,1 & 18,65 & 23,03 \\
\hline 25\% DE LODO 02 & 0,68 & 69 & 15.53 & 19,23 \\
\hline $50 \%$ DE LODO 02 & 0,72 & 5,2 & 15,30 & 18,18 \\
\hline
\end{tabular}

- Rompimento aos 7 dias $\quad$ Rompimento aos 28 dias

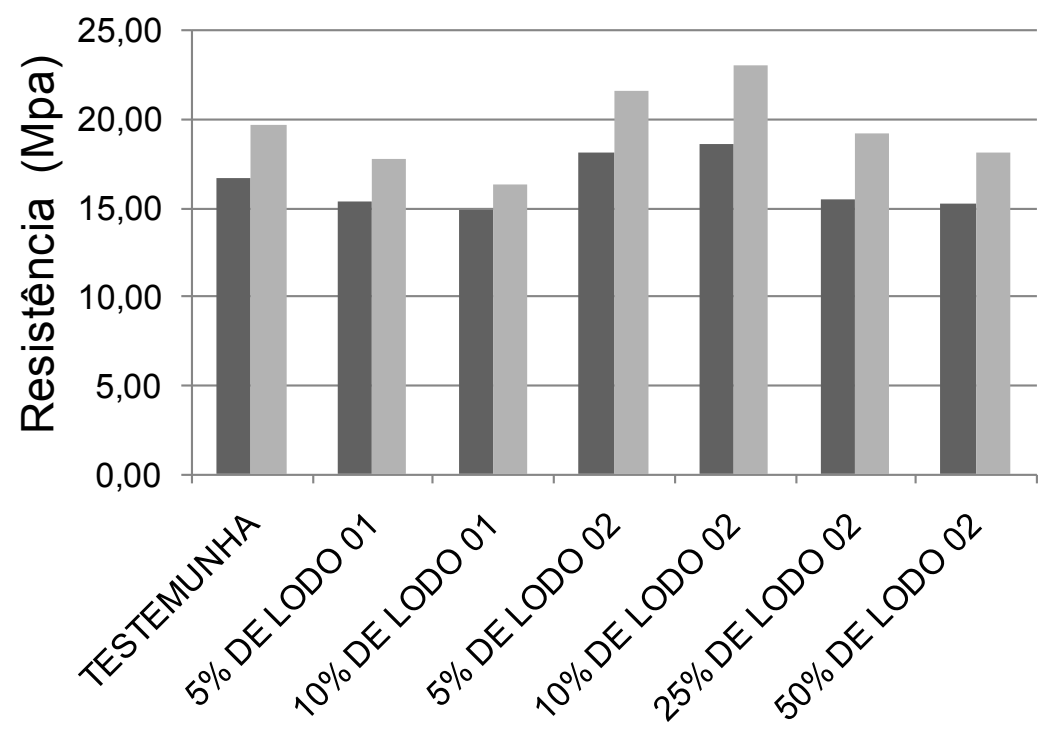

Figura 2 - Comparativo de resistências alcançadas. 
01 , na proporção de $5 \%$, apresentou queda na resistência à compressão ao comparar com os resultados do traço testemunha. Com $10 \%$ de substituição da areia pelo lodo 01, a queda de resistência se acentuou, sendo de apenas $16,4 \mathrm{MPa}$, sugerindo uma tendência de queda com aumento do teor de substituição.

Já os primeiros ensaios com substituição da areia pelo lodo 02 nas proporções de 5 e $10 \%$ foram animadores, elevando as resistências à compressão dos concretos, que foram de 21,65 $\mathrm{MPa}$ e 23,03 $\mathrm{MPa}$ respectivamente, em relação ao concreto testemunha, que foi de 19,7 MPa, dessa vez apresentando, então, expectativa de crescimento de resistência, à medida que se substituísse a areia pelo lodo 02 em maiores quantidades.

Rodando novos concretos, com proporções de 25 e $50 \%$ de lodo 02 substituindo a areia no traço, a expectativa não se confirmou e os rompimentos apresentaram queda na resistência à compressão em relação ao traço testemunha (Quadro 2).

Como sugerido por Bauer (1994), foi necessária a adição de quantidades maiores de água nos concretos rodados com lodo 01 , devido à maior presença de materiais finos, menores que $0,15 \mathrm{~mm}$, para que estes se enquadrassem no abatimento fixado de $60 \pm 10 \mathrm{~mm}, \mathrm{o}$ que acarretou em concretos com relação água/cimento mais alta. A porcentagem de material pulverulento do lodo $01,10,80 \%$, foi alta e, como proposto por Bauer (1994), culminou na descontinuidade da argamassa, que, aliada ao aumento da relação água/cimento, diminuiu a resistência do concreto. A Figura 2 mostra o comparativo das resistências encontradas.

Estudos utilizando sucata de vidro, na fabricação de concretos (Godoy et al., 2008), em substituição à areia, na proporção de $25 \%$, encontraram resistência, aos 28 dias, de 30,19 $\mathrm{MPa}$, ligeiramente inferiores aos $31,96 \mathrm{MPa}$ alcançados com o traço referência. Apesar da boa resistência encontrada, a sucata de vidro não foi capaz de aumentar a resistência em relação à referência com o lodo 02 , nas proporções de 5 e $10 \%$.

A exigência mínima para resistência de concretos utilizados em pavimentação de circulação de pedestres e veículos leves é de 7,5 $\mathrm{MPa}$ aos 28 dias, requisitos que os concretos testados alcançaram logo nos períodos iniciais de cura. (PAREJA et al.,2008)

\section{CONCLUSÕES}

A incorporação do lodo de indústria de concreto em seu processo produtivo proporcionará sua utilização no amassamento de concreto, deixando de ser um resíduo altamente danoso ao ambiente e se tornando um componente de substituição parcial de matéria prima (areia), reduzindo, assim, o impacto deste tipo de indústria no meio ambiente.

Deve-se ressaltar que a Norma Brasileira Agregados para Concreto - Especificações (NBR 7211, 2009) cita, como requisitos gerais, para agregados, a importância destes não conterem materiais de natureza e em quantidades que alterem a hidratação e o endurecimento do cimento, a proteção da armadura contra corrosão e durabilidade, sendo necessários ensaios como o de exame petrográfico para tais constatações. Este estudo limitou-se às principais características de resistência do concreto, indicando sua utilização em elementos não estruturais, em que não seja necessária armação, para a completa utilização do material deve se aguardar estudos complementares que abranjam além do escopo deste trabalho.

A baixa presença de materiais pulverulentos no lodo 02 garantiu o seu bom desempenho, obtendo o melhor resultado com $10 \%$ de substituição da areia, apresentando resistência, aos 28 dias, de 23,03 $\mathrm{MPa}$, $16,9 \%$ a mais que o concreto testemunha $(19,7 \mathrm{MPa})$. A maior quantidade de material passante pela peneira $1,19 \mathrm{~mm}$ do lodo 02 significou menor número de vazios, com aumento da compacidade e, consequentemente, da resistência final do concreto. Recomenda-se seu uso em caráter de teste em pavimentos com tráfego de pessoas e equipamentos leves e seu emprego em sarjetas.

Leva-se a crer que, para um traço referência de cerca de $30 \mathrm{MPa}$, como nos experimentos de Godoy et al. (2008), a substituição de parte da areia por lodo 02 , nas proporções de $5 \%$ e $10 \%$, mantenha a tendência de aumento das resistências referências, não ficando a substituição por este tipo de lodo limitada a traços de 20MPa de resistência à compressão.

\section{REFERÊNCIAS}

ABNT - ASSOCIAÇÃO BRASILEIRA DE NORMAS TÉCNICAS. NBR 5738. Concreto - Procedimento para moldagem e cura de corpos-de-prova. Rio de Janeiro, 2008.

ABNT - ASSOCIAÇÃO BRASILEIRA DE NORMAS TÉCNICAS. NBR 5739. Concreto - Ensaios de compressão de corpos-de-prova cilíndricos. Rio de Janeiro, 2007.

ABNT - ASSOCIAÇÃO BRASILEIRA DE NORMAS TÉCNICAS. NBR 7211. Agregados para concreto - Especificação. Rio de Janeiro, 2009.

ABNT - ASSOCIAÇÃO BRASILEIRA DE NORMAS TÉCNICAS. NBR NM 248/01: Agregados - Determinação da composição granulométrica. Rio de Janeiro, 2001. 
BAUER, L. A. F.; Materiais de Construção 1. $5^{\text {a }}$ edição. Rio de Janeiro: Editora LTC, 1994. 435p.

BRITO, J.A. Cidade versus entulho. In: SEMINÁRIO DE DESENVOLVIMENTO SUSTENTÁVEL E A RECICLAGEM NA CONSTRUÇÃO CIVIL, 2., São Paulo, 1999. Anais. São Paulo, Comitê Técnico CT206 Meio Ambiente (IBRACON), 1999. p.56-67.

CABRAL, A. E. B.; SCHALCH, V.; MOLIN, D. C. C.; RIBEIRO, J.L.D.; RAVINDRARAJAH, R. S.; Desempenho de concretos com agregados reciclados de cerâmica vermelha. Cerâmica. P. 448-460, 2009.

CONCRETO E CONSTRUÇÕES. Concreto: material construtivo mais utilziado do mundo. IBRACON, $n^{\circ} 53,2009$.

CONSELHO NACIONAL DO MEIO AMBIENTE - CONAMA. Resolução n ${ }^{\circ} 307$, de 5 de julho de 2002. Publicada no Duo n ${ }^{\circ} 136$, de $17 / 07 / 2002$ pgs 95-96.

CURWELL, S.; COOPER, I. The implications of urban sustainability. Building Research and Information. V.26, nº 1, 1998. p. 17-28.

GODOY, J. et al. Utilização de sucata de vidro na fabricação de argamassa. In:XII SIMPÓSIO DE ENSINO, PESQUISA E EXTENSÃO, SEPE 2008, UNIFRA, Santa Maria - RS.

GUNTHER, W.M.R. Minimização de resíduos e educação ambiental. In: SEMINÁRIO NACIONAL DE RESÍDUOS SÓLIDOS E LIMPEZA PÚBLICA, 7. Curitiba, 2000. Anais. Curitiba, 2000.

HOPPEN, C.; PORTELLA, F. K.; JOUKOSKI, A.; TRINDADE, E. M.; ANDREÓLI, C. V.; Uso de lodo de estação de tratamento de água centrifugado em matriz de concreto de cimento portland para reduzir o impacto ambiental. Quim Nova, Vol. 29, No.1, 79-84, 2006.

JOHN, V.M. Reciclagem de resíduos na construção civil - contribuição à metodologia de pesquisa $\mathrm{e}$ desenvolvimento. São Paulo, 2000. 102p. Tese (livre docência) - Escola Politécnica, Universidade de São Paulo.

MEHTA, P. K.; MONTEIRO, P. J. M.; Concreto: estruturas, propriedades e materiais. São Paulo: Editora Pini, 1994.
MOURA, W. A.; GONÇALVES, J. P.; LEITE, M. B.; Avaliação de propriedades mecânicas de concretos contendo escória de cobre como agregado miúdo. R. Esc. Minas, Ouro Preto, 62(2): p. 221-225, 2009.

PAREJA, J. A. M. et al. Substituição da areia por polietileno de alta densidade (PEAD) na produção de concreto.In:VI SIMPÓSIO DE ENGENHARIA AMBIENTAL, 2008, Serra Negra - SP.

PET-CIVIL UFJF. Programa de educação tutorial da engenharia civil da UFJF. Reaproveitamento de água para a produção de concreto. Juiz de Fora, 2012.

PINTO, T.P. Metodologia para a gestão diferenciada de resíduos sólidos da construção urbana. São Paulo, 1999. 189p. Tese (Doutorado) - Escola Politécnica, Universidade de São Paulo.

PMSP-SMSP - PREFEITURA MUNICIPAL DE SÃO PAULO, SECRETARIA DE COORDENAÇÃO DAS SUBPREFEITURAS DE SÃO PAULO. Calçadas da Avenida Paulista. Especificação e Procedimentos. Projeto de reforma das calçadas da Avenida Paulista. Rev.0, Julho de 2008.

Sindicato Nacional da Indústria do Cimento, disponível em http://www.snic.org.br/, acessado em 18/04/2013.

TENÓRIO, J. J. L.; GOMES, P. C. C.; RODRIGUES, C. C.; ALENCAR, T.F.F.; Concrete produced with recycled aggregates. Revista IBRACON de estruturas e materiais. Volume 5, p692-701, 2012.

UCKER, F. E.; LOPES, M. I. P.; BARROSO, L. B. Utilização do lodo gerado em indústria para a fabricação de argamassa. Disc. Scientia. Série: Ciências naturais e tecnológicas, Santa Maria, v.11, n.11, p-106114, 2010.

United Nations. General Assembly. Forty-second session. Development and international economic co-operation: environment. Report of the World Commission on Environment and Development. Disponível em, http://ambiente.files.wordpress. com/2011/03/brundtland-report-our-common-future. pdf, acessado em 10/05/2013.

Willmont Dixon Group. The Impact sod Construction and the built environment. Disponível em: http:// www.willmottdixongroup.co.uk/assets/b/r/briefing-note-33-impacts-of-construction-2.pdf, acessado em 23/05/2013. 